and lower to pathology than expected from the general increase in the hospital specialties.

This cohort was surveyed for the first time several years into the qualifiers' medical careers. We are cautious about interpreting recalled career choices because they may be influenced by the passage of time. None the less, the decline in choice of general practice as a first career between 1983 and 1988 and between 1988 and 1993 suggests that interest in general practice among newly qualified doctors has fallen gradually.

We showed that, by 1995, the number of 1988 qualifiers who had left the NHS was no higher than that of 1983 qualifiers by 1990. However, there was a small but significant increase in the percentage of male doctors who were not in medical practice.

We thank all the doctors who participated. We thank Janet Justice and Alison Stockford for coding data, Karen Hollick for help with tables, and Jean Davidson for assisting with programming.

Contributors: Both authors designed the survey. TWL coordinated the conduct of the study, analysed the data, wrote the first draft of the manuscript, and contributed to further drafts. MJG suggested the use of capture-recapture methods and contributed to further drafts of the manuscript. Both authors will act as guarantors for the paper.

Funding: The UK Medical Careers Research Group is funded by the Department of Health. The Unit of Health-Care Epidemiology is funded by the Anglia and Oxford Regional Office of the NHS Executive.

Competing interests: None declared.

\section{Appendix}

Capture-recapture estimates of numbers of 1988 qualifiers working in NHS in Great Britain in 1995 were calculated, as shown in the table (above right), from numbers of doctors known to the Medical Careers Research Group and to the Department of Health.

Confidence intervals for the number of doctors in the NHS were obtained by calculating the standard error of $d$ using the formula

$$
S E=\sqrt{\frac{b c(a+b+1)(a+c+1)}{(a+1)^{2}(a+2)}}
$$

Capture-recapture estimates of numbers of 1988 qualifiers working in NHS in Great Britain in 1995

\begin{tabular}{lcccc} 
Group & Denoted by & Men & Women & Total \\
\hline Known to MCRG and DoH & $a$ & 990 & 815 & 1805 \\
\hline Known to MCRG but not to DoH & $b$ & 228 & 314 & 542 \\
\hline Known to DoH but not to MCRG & $c$ & 322 & 169 & 491 \\
\hline Estimated additional doctors in NHS & $d=b c /(a+1)$ & 74 & 65 & 147 \\
\hline Estimated total & $T=a+b+c+d$ & 1614 & 1363 & 2985 \\
\hline Known total population (cohort size) & $P$ & 1961 & 1632 & 3593 \\
\hline Participation rate $(\%)$ & $R=100 \mathrm{~T} / P$ & 82.3 & 83.5 & 83.1 \\
\hline Loss $(\%) \dagger$ & $L=100-R$ & 17.7 & 16.5 & 16.9
\end{tabular}

MCRG=Medical Careers Research Group; DoH=Department of Health.

*Unrecorded by both MCRG and DoH. The total estimated additional doctors $(n=147)$ does not exactly equal the sum of separate estimates for men $(n=74)$ and women $(n=65)$. This is a consequence of the higher response rate to our surveys from women than from men. Estimates for subpopulations in capture-recapture methods do not total to estimates for pooled populations, if individuals in each subpopulation differ in their likelihood of being observed.[6] The effect on estimated loss rates is small. †Estimated using known cohort size of qualifiers in Great Britain.

and multiplying by 1.96 to give the half width of a $95 \%$ confidence interval.

For example, the half width of the confidence interval for the total of 1988 qualifiers in the NHS in 1995 is 31 doctors; the $95 \%$ confidence interval for the total is therefore $2985 \pm 31$-that is, 2954 to 3016 , or $82.2 \%$ to $83.9 \%$ of the 1988 cohort of 3593 doctors.

1 Medical Workforce Standing Advisory Committee. Planning the medical workforce-third report. London: Department of Health, 1997.

2 Parkhouse J. Doctors' careers: aims and experiences of medical graduates. London: Routledge, 1991.

3 Lambert TW, Goldacre MJ, Parkhouse J, Edwards C. Career destination in 1994 of United Kingdom medical graduates of 1983: results of a questionnaire survey. BMJ 1996;312:893-7.

4 Hook EB, Regal RR. The value of capture-recapture methods even for apparent exhaustive surveys. Am J Epidemiol 1992;135:1060-7.

5 Lambert TW, Goldacre MJ, Edwards C, Parkhouse J. Career preferences of doctors who qualified in the United Kingdom in 1993 compared with those of doctors qualifying in 1974, 1977, 1980 and 1993. BMJ 1996;313:19-24.

6 Hook EB, Regal RR. Effect of variation in probability of ascertainment by sources ("variable catchability") upon "capture-recapture" estimates of prevalence. Am J Epidemiol 1993;137:1148-66.

(Accepted 28 July 1998)

\title{
Reducing maternal mortality: reaudit of recommendations in reports of confidential inquiries into maternal deaths
}

Angie Benbow, Michael Maresh

The development of clinical audit over the past 10 years has led to questioning of the role of the triennial reports of the confidential inquiries into maternal deaths. Recently, the maternal death rate has been 6-7 per 100000 maternities, with the proportion of deaths attributed to substandard care remaining around $40 \%$ To investigate the uptake of the recommendations of the confidential inquiries into maternal deaths Hibbard and Milner audited the facilities in consultant maternity units in the United Kingdom in 1993, including the availability of clinical guidelines for two major maternal complications, eclampsia and haemorrhage. ${ }^{1}$ This audit followed the publication of Maternal Mortality-the Way Forward ${ }^{2}$ and was published around the time the Royal College of Obstetricians and Gynaecologists produced Deriving Standards from the Maternal Mortality Report ${ }^{3}$ and the Department of Health the Report on Confidential Enquiries into Maternal Deaths in the United Kingdom 1988-1990. ${ }^{4}$ We investigated whether these national initiatives had had any effect on the implementation of the recommendations.

\section{Subjects, methods, and results}

A questionnaire was circulated during November 1996 to the heads of midwifery at all 325 hospitals listed on the unit's database. The response rate was $100 \%$ after one postal reminder and one telephone call to
Royal College of Obstetricians and Gynaecologists Clinical Audit Unit, St Mary's Hospital, Manchester M13 0JH

Angie Benbow, research fellow Michael Maresh, honorary director

Correspondence to: Dr Maresh audit@rcog.cmhct. nw.nhs.uk

BMJ 1998;317:1431-2 
Facilities by region in 1997 and $1993 .{ }^{1}$ Values are numbers (percentages) of maternity units

\begin{tabular}{|c|c|c|c|c|c|c|c|c|c|c|c|c|c|}
\hline & & $\begin{array}{l}\text { Northern } \\
\text { and } \\
\text { Yorkshire }\end{array}$ & $\begin{array}{c}\text { West } \\
\text { Midlands }\end{array}$ & North West & Trent & $\begin{array}{l}\text { Anglia } \\
\text { and } \\
\text { Oxford }\end{array}$ & $\begin{array}{l}\text { South and } \\
\text { West }^{*}\end{array}$ & $\begin{array}{l}\text { North } \\
\text { Thames }\end{array}$ & $\begin{array}{l}\text { South } \\
\text { Thames }\end{array}$ & Wales & $\begin{array}{l}\text { Northern } \\
\text { Ireland }\end{array}$ & Scotland & $\begin{array}{c}\text { United } \\
\text { Kingdom }\end{array}$ \\
\hline \multirow{2}{*}{ Total No of maternity units } & 1993 & 36 & 21 & 28 & 16 & 18 & 21 & 30 & 32 & 17 & 17 & 24 & 260 \\
\hline & 1997 & 29 & 19 & 31 & 18 & 20 & 23 & 31 & 32 & 16 & 14 & 26 & 259 \\
\hline \multirow{2}{*}{ Participating maternity units } & 1993 & $36(100)$ & $20(95)$ & $26(93)$ & $15(94)$ & $18(100)$ & $19(90)$ & $27(90)$ & $29(91)$ & $17(100)$ & $17(100)$ & $24(100)$ & $248(95)$ \\
\hline & 1997 & $29(100)$ & $19(100)$ & $31(100)$ & $18(100)$ & $20(100)$ & $23(100)$ & $31(100)$ & $32(100)$ & $16(100)$ & $14(100)$ & $26(100)$ & $259(100)$ \\
\hline \multirow{2}{*}{ Acute hospital on site } & 1993 & $31(86)$ & $20(100)$ & $23(88)$ & $14(93)$ & $16(89)$ & $17(89)$ & $21(78)$ & $26(90)$ & $14(82)$ & $16(94)$ & $15(63)$ & $213(86)$ \\
\hline & 1997 & $25(86)$ & $18(95)$ & $26(84)$ & $17(94)$ & $20(100)$ & $23(100)$ & $29(94)$ & $30(94)$ & $16(100)$ & $12(86)$ & $19(73)$ & $235(91)$ \\
\hline \multirow{2}{*}{ Intensive care unit on site } & 1993 & $29(81)$ & $17(85)$ & $19(73)$ & $11(73)$ & $16(89)$ & $14(74)$ & $21(78)$ & $24(83)$ & $13(76)$ & $11(65)$ & $13(54)$ & $188(76)$ \\
\hline & 1997 & $23(79)$ & $16(84)$ & $23(74)$ & $16(89)$ & $18(90)$ & $21(91)$ & $26(84)$ & $27(84)$ & $13(81)$ & $10(71)$ & $13(50)$ & $206(80)$ \\
\hline \multirow{2}{*}{ Blood bank on site } & 1993 & $31(86)$ & $20(100)$ & $22(85)$ & $13(87)$ & $16(89)$ & $16(84)$ & $23(85)$ & $26(90)$ & $15(88)$ & $15(88)$ & $19(79)$ & $216(87)$ \\
\hline & 1997 & $28(97)$ & $19(100)$ & $29(94)$ & $18(100)$ & $19(95)$ & $23(100)$ & $29(94)$ & $32(100)$ & $16(100)$ & $12(86)$ & $24(92)$ & $249(96)$ \\
\hline \multirow{2}{*}{ Eclampsia protocol available } & 1993 & $33(92)$ & $19(95)$ & $26(100)$ & $13(87)$ & 17 (94) & $18(95)$ & $27(100)$ & $26(90)$ & $17(100)$ & $11(65)$ & $18(75)$ & $225(91)$ \\
\hline & 1997 & $28(97)$ & $17(89)$ & $29(94)$ & $17(94)$ & $20(100)$ & $23(100)$ & $28(90)$ & $30(94)$ & $16(100)$ & $12(86)$ & $23(88)$ & $243(94)$ \\
\hline \multirow{2}{*}{$\begin{array}{l}\text { Haemorrhage protocol } \\
\text { available }\end{array}$} & 1993 & $32(89)$ & $17(85)$ & $25(96)$ & $11(73)$ & $15(83)$ & $18(95)$ & $25(93)$ & $27(93)$ & $15(88)$ & $4(24)$ & $15(63)$ & $204(82)$ \\
\hline & 1997 & $29(100)$ & $17(89)$ & 29 (94) & $16(89)$ & $20(100)$ & $21(91)$ & $26(84)$ & $28(88)$ & $16(100)$ & $13(93)$ & $25(96)$ & $240(93)$ \\
\hline
\end{tabular}

*Includes Channel Islands. †Not audited in 1993.

non-respondents during March 1997. We identified 259 consultant maternity units among these 325 hospitals. We excluded data from units that were not led by consultants because they were incomplete, mainly owing to changes occurring as units closed or were redesignated.

Early in 1997, 235 of the 259 units (91\%) were on the site of an acute general hospital, compared with 213 out of $248(86 \%)$ in 1993 (table). Overall, 150 maternity units had between 2000 and 4000 deliveries per annum, with 63 having fewer than 2000 and 46 more than 4000 . There was an intensive therapy unit on site in 206 of the units (80\%) in 1997 compared with $188(76 \%)$ in 1993. In addition, $249(96 \%)$ had blood transfusion services on site compared with 216 $(87 \%)$ in 1993 . The nearest blood transfusion service for the other 10 units was 2-35 km away, with five services being more than $8 \mathrm{~km}$ away. Clinical guidelines were available for the management of major haemorrhage in 240 (93\%) units and for eclampsia in 243 (94\%) units in 1997 compared with 204 (82\%) and 225 (91\%) respectively in 1993.

In 1997, 239 units had easy access to the Cochrane Library, with 133 having the library available in the clinical area. A total of 244 units had a copy of the confidential inquiry into maternal deaths, with 241 finding it useful for developing guidelines.

\section{Comment}

This audit has shown that the availability of services planned to minimise maternal risk are improving. These changes are likely to have at least in part resulted from the audit cycle and the publication and wide distribution of the various recommendations. ${ }^{1-4}$ These efforts will, we hope, result in a further reduction in maternal deaths, and we believe that continuation of the confidential inquiries is justified. Audit of maternal morbidity is currently being evaluated in several exercises. ${ }^{5}$

The recommendation to have all consultant maternity units in acute hospitals has now been achieved in Wales and in two English regions, and it has almost been achieved throughout the rest of the United Kingdom apart from Scotland. The availability of blood transfusion services has improved. The availability of guidelines on eclampsia and major haemorrhage has increased, but some units did not have them. Some heads of midwifery did not have access to the reports on confidential inquiries into maternal deaths despite every trust being sent one.

Contributors: $\mathrm{AB}$ helped design the study, conducted the survey and follow up of non-respondents, conducted the analysis, and jointly wrote the paper. MM helped in the design of the study, advised on the survey, helped interpret the data, jointly wrote the paper, and is the guarantor for the content of the paper. Dr Gwyneth Lewis, principal medical officer for women's health services at the Department of Health, advised on the undertaking and design of this study.

Funding: Department of Health core clinical audit grant. Competing interests: None declared.

1 Hibbard B, Milner D. Reports on confidential enquiries into maternal deaths: an audit of previous recommendations. Health Trends 1994;26(1):26-8.

2 Patel N, ed. Maternal mortality-the way forward. Some implications of the report on confidential enquiries into maternal deaths in the United Kingdom 1985-87. London: Royal College of Obstetricians and Gynaecologists, 1992.

3 Royal College of Obstetricians and Gynaecologists. Deriving standards from the maternal mortality report. Manchester: RCOG Clinical Audit Unit, 1994.

4 Department of Health. Report on confidential enquiries into maternal deaths in the United Kingdom 1988-1990. London: HMSO, 1994.

5 Waterstone M, Bewley S, Wolfe C. Preliminary results from a one year prospective study of the incidence of severe obstetric mortality. BrJ Obstet Gynaecol 1998;105 (suppl 17):35. (Abstract 88.)

(Accepted 14 August 1998)

\section{Endpiece \\ A little bit of luck}

What need has medicine of luck? If there are drugs clearly appropriate for illnesses, I think that drugs do not depend on luck to turn the illnesses to health, if there are indeed drugs. But if there is any use in prescribing with mere luck, drugs no more than non-drugs with luck will make the patient well, when applied to illnesses.

Hippocrates, Places in Man, edited and translated by Elizabeth M Craik, 1998

Submitted by Ann Dally, Wellcome Institute for the History of Medicine 